\title{
Analysis of 5 Floors Brick Masonry Building Type 77/5
}

\author{
Petraq Koka, Nikolla Vesho, and Fabion Shehu
}

\begin{abstract}
The study below presents the main results of numerical analyzes, performed to assess the seismic response of an existing building, with brick masonry, type 77/5. This building is part of the group of 4-5 residential buildings, built in the years 1975-1990, considered as a "TYPE", each of which was used many times for identical buildings.

This project is the result of a collective work of the Design Institute, approved by the Ministry of Construction of that time, and of course, manifests the time limitations and shortcomings.

While these 5-story buildings cover a significant percentage of residential buildings, the fundamental question is: "Are these buildings safe under seismic action, while so many families are accommodated on them?"

This question stems from the following limitation:

- The 77/5 plan derives from regular forms, based on the recommendations of Eurocode 8 [4.2.3.2], p.48, and KTP.N.2-89 (Technical Design Conditions), published by the Academy of Sciences of Albania.

- The technical literature provides recommendations and restrictions for masonry buildings with a height of not more than 3 floors. When they exceed this height, they are not included in these recommendations.
\end{abstract}

Key words - brick masonry, building, Eurocode, linear analysis.

\section{INTRODUCTION}

Masonry structures represent one of the oldest building concepts available. Masonry construction is a traditional, widely used, extremely flexible, and economical construction method.

However, possibly due to the substantial empirical knowledge collected over several centuries of the utilization of masonry as a structural material, the need for establishing a more modern basis, for the design of masonry structures, hasn't been appreciated in the same manner as for concrete structures. As a result, conventional masonry design practice is overly conservative, particularly regarding the assessment of seismic resistance.

Hence, the potential of masonry has not yet been fully exploited and there is a clear need for better utilization.

Meanwhile, for nonlinear analysis, based on the author Thomas Zimmermann [3], is accepted the value: $\left.\mathrm{E}=300 \mathrm{fk}\left[\mathrm{N} / \mathrm{mm}^{2}\right]\right)$, as closest to the experimental results.

$$
\mathrm{E}=1000 \mathrm{fk} \mathrm{N} / \mathrm{mm}^{2}
$$

So, for the cases in study, do to:

- Bricks - Class $=7.5 \mathrm{~N} / \mathrm{mm}^{2}$ (not perforated, clay

Submitted on July 01, 2021.

Published on July 22, 2021.

Petraq Koka, Building Engineer, a former lecturer at Polytechnic University \& Polis University, Lecturer at UET University, Technical director of "Speed Engineers" Itd., Tirana, Albania.

(e-mail: petraq.koka ${ }^{@}$ gmail.com) material);

- Cement mortar - Class $=2.5 \mathrm{~N} / \mathrm{mm}^{2}$;

The elasticity modulus, will be:

- for the linear case: $\mathrm{E}=1000 \times 1,1=1100 \mathrm{~N} / \mathrm{mm}^{2}$;

- for the nonlinear case: $\mathrm{E}=300 \times 1,1=330 \mathrm{~N} / \mathrm{mm}^{2}$;

(The behavior of the mortar depends a lot on the binder used, its quality, and quantity [3]).

- The loads acting on the slabs are:

- Dead load $=2 \mathrm{kN} / \mathrm{m}^{2}$;

- Live $=2 \mathrm{kN} / \mathrm{m}^{2}$

- Additional dead load $=2 \mathrm{kN} / \mathrm{m}^{2}$.

\begin{tabular}{ccccccccc}
\multicolumn{8}{c}{ TABLE I: FK VALUES } \\
\hline $\mathrm{Nr}$ & $\begin{array}{c}\text { Brick class } \\
\left(\mathrm{N} / \mathrm{mm}^{2}\right)\end{array}$ & \multicolumn{7}{c}{ Mortar class $\left(\mathrm{N} / \mathrm{mm}^{2}\right)$} \\
\hline & & 10 & 7.5 & 5.0 & 2.5 & 1.5 & 0.4 & 0.0 \\
3 & 7.5 & 1.5 & 1.4 & 1.3 & 1.1 & 0.9 & 0.7 & 0.5 \\
\hline
\end{tabular}

For example, while current codes of practice severely limit the use of unreinforced masonry (URM) in construction, mainly, because of the requirement of over-conservative values, for the force-reduction factor ( $q$-factor), recent studies designed low-rise URM buildings should be considered adequate for the category of show that the performance of structurally-ordinary buildings, even in regions with appreciable seismic hazard [8].

The full study includes analyzes based on 3 steps:

- Linear analysis, with the help of finite element model (Etabs Program).

- Nonlinear analysis performed with a simplified modeling procedure (AM-Quake).

- Ways to strengthen the building, converting it into a stable building, following EC 6.8.

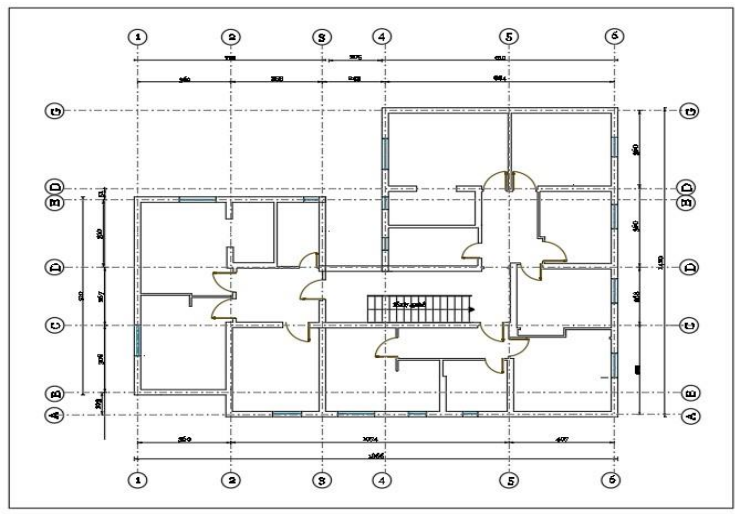

Fig. 1. Typical floor plan.

Nikolla Vesho, Former Engineer at "Speed Engineers"ltd, Lecturer at Polis University, Tirana, Albania.

(e-mail: nikollavesho@gmail.com)

Fabion Shehu, Civil Engineer at "Speed Engineers" 1td, Tirana, Albania. (e-mail: fabishehu ${ }^{\circledR}$ protonmail.com) 


\section{MATERIAL AND METHODS}

Masonry structure is a heterogeneous material, due to its 2 components, bricks and mortar consequently represent a behavior highly dependent on the reaction of these constituents.

However, we consider it as a homogeneous anisotropic material in terms of resistance and deformation.

\section{How ThIS BUILDING Is BuILT}

- The building ground and first-floor walls are $38 \mathrm{~cm}$ thick.

- The walls, from the first floor to the fourth, are $25 \mathrm{~cm}$ thick.

Based on all restrictions about these 2 materials, from Table I, we accepted for the masonry compressive strength the value:

$$
f k=1.1 \mathrm{~N} / \mathrm{mm}^{2}[5]
$$

In EC6, the elasticity modulus of masonry E, for service conditions, is recommended:

- On top of the masonry, of each floor, there are concrete girdle $(38 \times 15)$ and $(25 \times 15) \mathrm{cm}$, depending on the wall thickness.

- The slabs are type, Zoellner. They consist of perforated bricks, filled between each row with reinforced concrete. The concrete compressive strength is accepted relatively low, $\mathrm{C} 15 / 20$, (due to out of standards compounds quality, at that time).

\section{A. Seismic Data}

Based on the EC recommendation [6] we choose the type "1" of the earthquake, with magnitude MS > 5.5. So:

- acceleration ag $-0.25 \mathrm{~g}$.

- the masonry ductility factor $\mathrm{q}=\mathrm{q} 0 \mathrm{kw} \geq 1.5$, and

- extinction 3\% [6].

For the case of Tirana land, based on the Institute of Geosciences data, is accepted:

- land type - category $\mathrm{C}$.

\section{B. Linear Analysis}

Poor tensile strength of masonry requires a good knowledge of its characteristics and the correct use of linear elastic models, to predict the reaction and damage of a building, subject to seismic actions. From this point of view, the use of a finite element model, for the study of the stressed state under the action of static loads and the modal behavior of the building, in the linear field, is of interest [6].

The use of the ETABs program serves this intention.

But the linear analysis is not the purpose of this presentation.

So, we will present shortly only the main results of this program.

\section{1) Displacement}

(With gray lines the deformed shape of the building is presented)

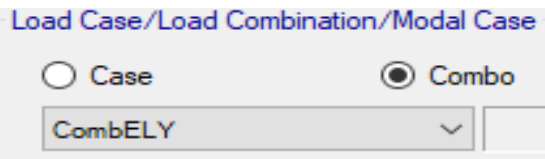

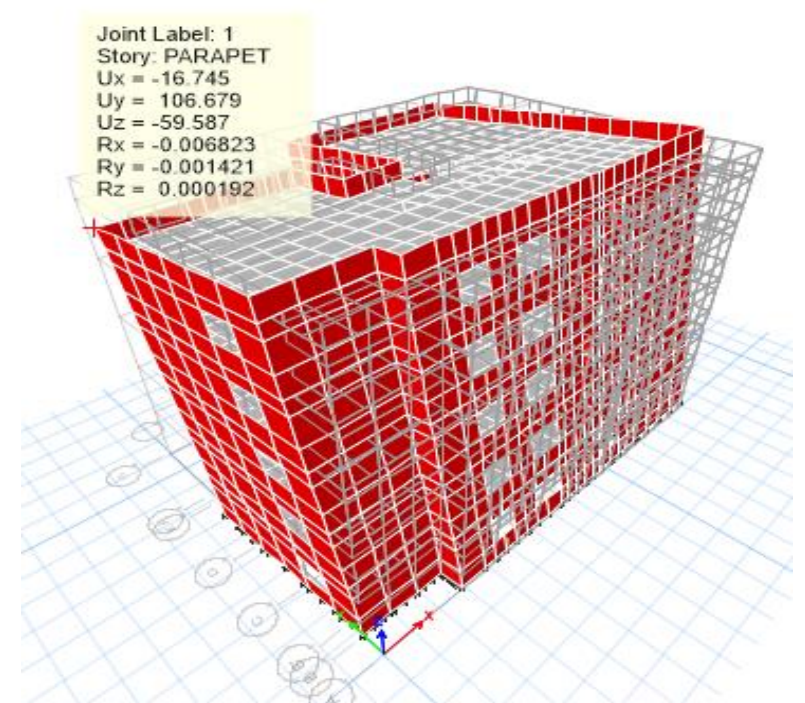

Fig. 2. The displacements on the joint 1, for the case Comb ELY.

If we accept that the allowed horizontal displacements should be $1 / 200 \mathrm{H}$ of the building, then we have:

$$
\mathrm{H} / 200=1420 \mathrm{~cm} / 200=7.1 \mathrm{~cm}
$$

Meanwhile, the maximum displacement, for the comb:

$$
\begin{gathered}
\mathrm{ELY}=\mathrm{D}+0.3 \mathrm{~L}+0.3 \mathrm{EQLX}+\mathrm{EQLY} \text { is: } \\
\mathrm{Uy}=10.67 \mathrm{~cm} \gg 7.1 \mathrm{~cm}
\end{gathered}
$$

\section{2) Periods}

From the results of the modal analysis, we found that the building, for the combination ELY, manifests high periods in the first form of oscillation:

$$
\mathrm{T}=0.689 \mathrm{~s}
$$

\section{Mode 1 - Period 0.688960526380029}

Based on the Eurocode recommendation, the theoretical allowed period of the masonry building should be:

$[\mathrm{T}]=0.05 \mathrm{H}^{3 / 4}=0.05 \times 14.2^{3 / 4}=0.365 \mathrm{sec}<<\mathrm{T}=0.690 \mathrm{~s}$,

where $\mathrm{H}=14.2$ meters, is the total height of the building. $E L Y=$ Equivalent lateral earthquake in the $Y$ direction

\section{3) The stresses}

Due to the limited volume of publication, we are not quoting all the points endangered by high traction and compression stresses, but only one, to illustrate and expose the level that these stresses reach. 


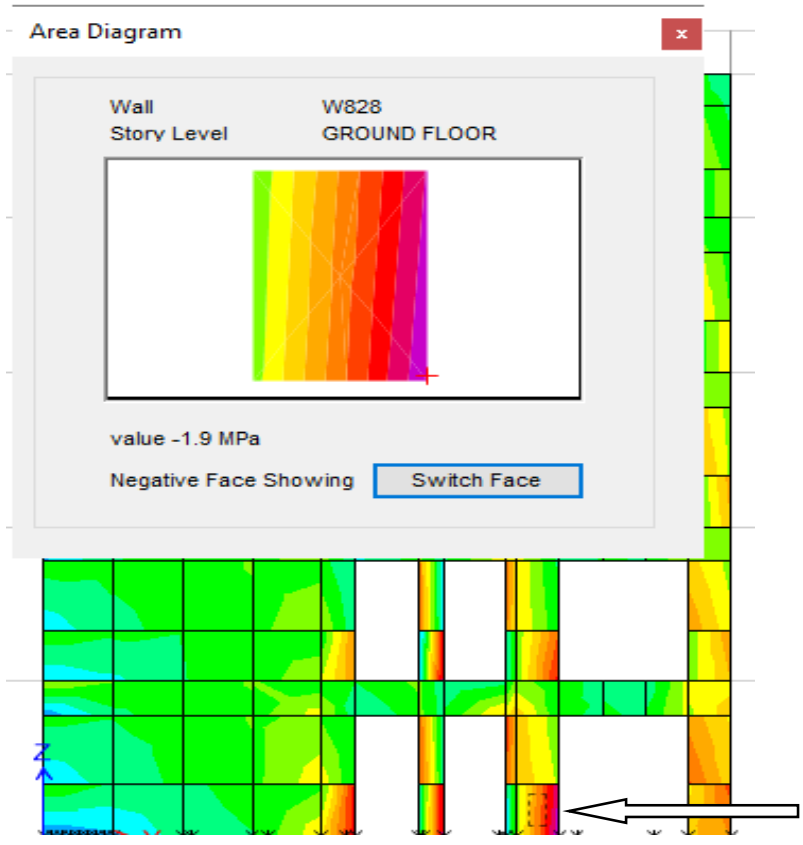

$\mathrm{S}_{11}=-1.9 \mathrm{MPa}$

Fig. 3. Wall on axis 2 and the most stressed element in it W828.

\section{Nonlinear Analysis}

A significant influence on the way the masonry should be analyzed, especially in the nonlinear field, had the first edition of the author Tomaževic, 1978.

("POR Method ").

The method conceives a masonry building composed of "macroelements". All the structure is schematized from equivalent frames consisting of:

-[piers] - "the walls" part of vertical masonry, located between the two windows, which work from floor to floor, in parallel.

[spandrel] - continuous horizontal bandage, located between the windows of each floor.

Numerical programs, based on this method, analyze the model divided into macro-elements, piers, and spandrels, which generally require the comparison of the seismic demand with the building capacity, in terms of displacements.

The definition of the displacement capacity can be achieved employing a non-linear static analysis (pushover analysis), applying to the structure lateral loads, distributed, linearly increasing, describing the seismic forces [8].

Among the programs that are based on these principles, as more convenient and available for this purpose we chose the Am-quak method.

In the AM-quake program, these slabs are considered as rigid horizontal structures, they transmit lateral load (earthquake) to the retaining walls.

An important step in preparing the input data for Am Quake analysis is the idealization of the structure, based on the theory of Equivalent Frames.

The red lines in it represent beam elements and gray lines indicate links between them. Bearing walls are modeled by vertical columns. Each wall with a window is typically modeled by two beams, one for parapet and one for lintel part. Horizontal beams in the model are also used for RC rings at ceilings.
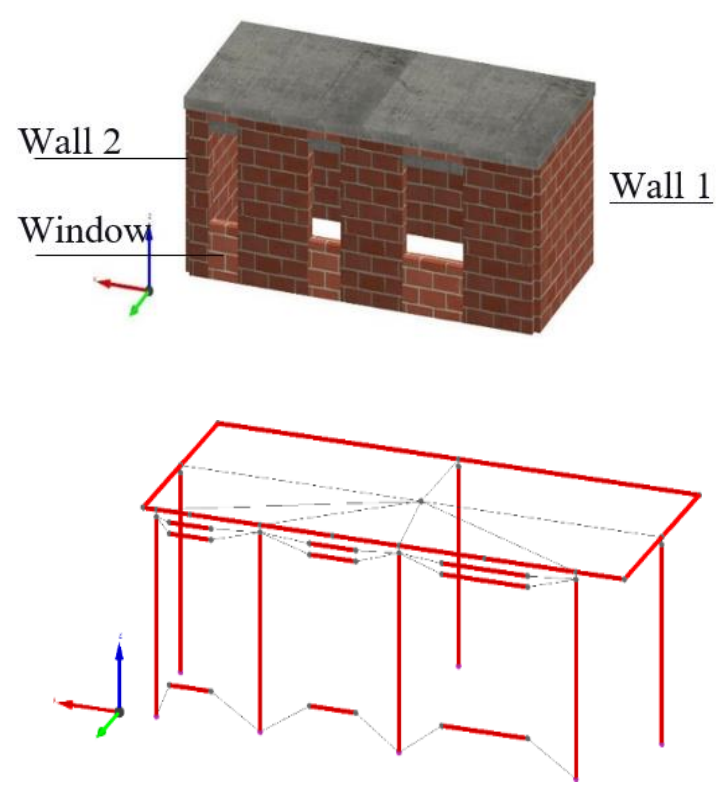

Fig 4. 3D and wire model of a sample structure.

Based on this method basic principles, we schematized the BUILDING $77 / 5$ in equivalent frames (PIERS and SPANDRELS), as below:
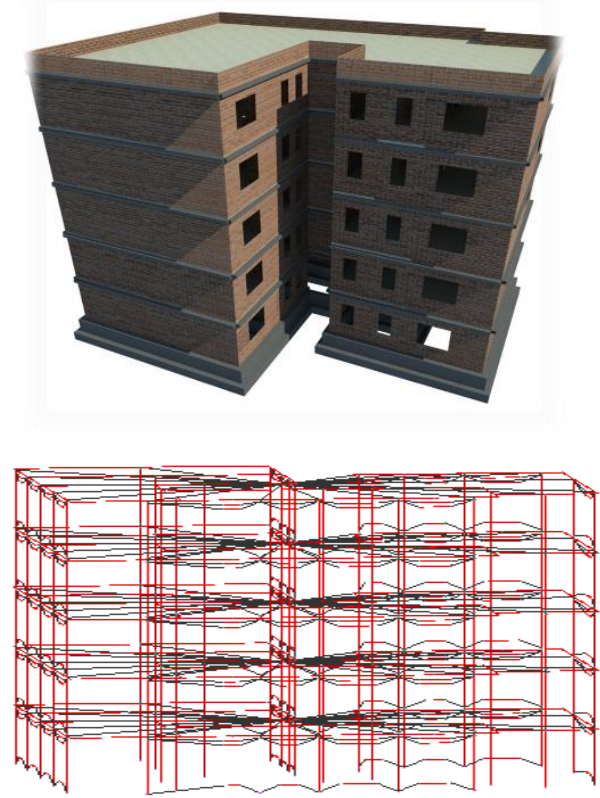

Fig. 5. $3 D$ view of building $77 / 5$ and the front view schematization.

The Pushover analysis for combination_(1) $\mathrm{X}+$, exc, pos, uni

\begin{tabular}{ll}
\hline (5) X-, exc. pos, uni & \\
DLS target $[\mathrm{mm}]:$ & 4.035 \\
\hline DLS capacity [mm]: & 17.437 \\
Damage limit state: & Pass \\
& \\
ULS target $\times 1.50[\mathrm{~mm}]:$ & 14.552 \\
ULS capacity $[\mathrm{mm}]:$ & 17.437 \\
Ultimate limit state: & Pass
\end{tabular}

Fig. 6. The results of AM-quake. 


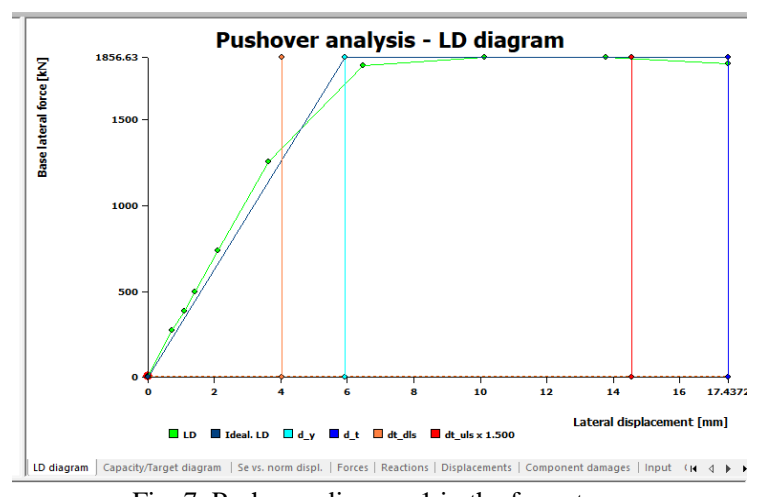

Fig. 7. Pushover diagram 1 in the format.

The Pushover analysis for combination (9) $\mathrm{Y}+$, exc, pos, $\underline{\text { uni }}$

\begin{tabular}{ll}
\hline (9) Y+, exc. pos, uni & \\
DLS target [mm]: & 25.634 \\
DLS capacity [mm]: & 68.219 \\
Damage limit state: & Pass \\
ULS target x 1.50 [mm]: & 76.901 \\
ULS capacity [mm]: & 63.656 \\
Ultimate limit state: & Fail
\end{tabular}

Fig. 8. The results of AM-quake for of AM-quake combination (9).

- DLS target - Top floor displacement, at which the interstory drifts for each floor are checked if they don't violate the damage limitation requirement.

- DLS capacity - Top floor displacement when the interstory drift for a certain floor violates the damage limitation requirements.

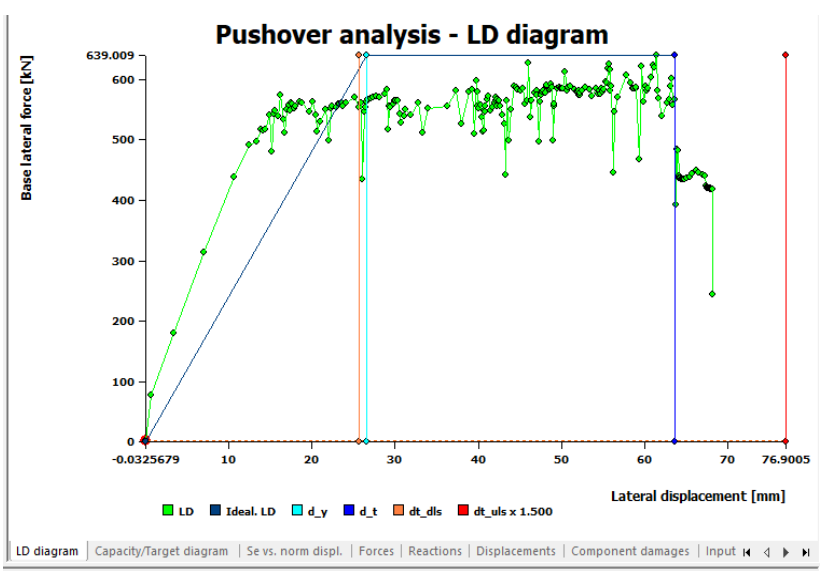

Fig. 9. Pushover diagram in the format of AM-quake, for combination (9).

- ULS target - Top floor displacement that can be expected for the given structure and seismic demand.

Ld - diagram-lateral displacement diagram.

Dy -yeld displacement. dt_dls - target displacement for DLS.

dt_uls - target displacement for ULS.

$\mathrm{dt}-$ target displacement.

D. The technical Proposals for the Improvement of Displacements and Period Parameters

The surface of the resistant masonry, in each orthogonal direction, for an ordinary 3-story masonry building, for ground acceleration $\mathrm{a}=0.25 \mathrm{~g}$, for each direction, should be 6\% (Table II) [1].

During several years of research in the technical literature for masonry buildings, we haven't encountered other recommendations about the maximum percentage of masonry in addition to the table above, for buildings higher than 3 floors. I think the reason is the fact that various authors have ruled out the possibility to build masonry buildings more than $10 \mathrm{~m}$, in seismic areas.

Based on the 26.11.2019 earthquake observations, these types of buildings, when on their ground floors no reducing masonry interventions were made, reacted relatively well.

The only factor that may have had a positive effect, is the percentage of masonry, which is $17 \%$ and $18 \%$ in each direction.

Anyway, it is paradoxical how this high percentage of masonry allows the building to have periods twice as high as allowed!! This will be the subject of further analysis.

This conclusion does not exclude sudden collapse by seismic force, as long as the building manifests significant structural deficiencies, which are manifested in high periods, twice as much as allowed

To improve the above parameters, in the linear analysis, the following steps were followed:

1. It was presumed that the masonry has a high modulus of elasticity, twice as much as that of the EC6 recommendation. Thus, the elasticity modulus E $2200 \mathrm{MPa}$ was taken into account.

$a$. Its impact was of little importance in reducing the period, so the period goes down only to the level $\mathrm{T}=0.566$ sec.

\section{Mode 1 - Period 0.566201858962981}

However, this is a hypothetical version, because improving the characteristics of the masonry is practically impossible

$b$. The displacements are significantly improved, for the most unfavorable case, ELY combination we have:

$$
\operatorname{Max}=78.257 \text { at }[7.17,0,14.6] ; \text { Min }=-59.867 \text { at }[9.7,13.87,13.2222]
$$

$c$. The stresses on the most vulnerable elements improv`ed significantly. So, in axis 2-2, which was problematic, were greatly reduced, for most unfavorable combination.

\begin{tabular}{|c|c|c|c|c|c|c|c|c|c|c|c|}
\hline \multirow{2}{*}{\multicolumn{2}{|c|}{$\begin{array}{c}\text { Acceleration at the top of the } \\
\text { terrain ag S }\end{array}$}} & $\leq 0,07$ & $\leq 0,1$ & $\leq 0,15$ & $\leq 0,20$ & $\leq 0,25$ & $\leq 0,30$ & $\leq 0,35$ & $\leq 0,40$ & $\leq 0,45$ & $\leq 0,47$ \\
\hline & & g & $\mathrm{g}$ & g & g & g & g & g & g & $\mathrm{g}$ & $25 \mathrm{~g}$ \\
\hline \multicolumn{12}{|c|}{ Type of structure Floors No. } \\
\hline & 1 & $3,5 \%$ & $3,5 \%$ & $4,0 \%$ & $4,5 \%$ & $5,0 \%$ & $5,5 \%$ & $6,0 \%$ & $6,0 \%$ & $6,0 \%$ & $6,5 \%$ \\
\hline \multirow[t]{2}{*}{ Ordinary masonry } & 2 & $4,0 \%$ & $4,0 \%$ & $4,5 \%$ & $5,0 \%$ & $5,5 \%$ & $6,0 \%$ & $6,5 \%$ & $6,5 \%$ & $6,5 \%$ & $7,0 \%$ \\
\hline & 3 & $4,5 \%$ & $4,5 \%$ & $5,0 \%$ & $5,5 \%$ & $6,0 \%$ & $6,5 \%$ & $7,0 \%$ & & & \\
\hline
\end{tabular}


Acceleration at the top of the terrain ag SELY we have:

$\operatorname{Max}=0.21$ at $[3.6,6.5756,13.8]$ : Min $=-0.59$ at $[3.6,7.34,0]$

2. Some Authors recommended the use of FRP for the reinforcement of these masonry buildings. This idea, in my opinion, is practically unfeasible because FRP has these negative sides

$a$. Has high costs, especially when it comes to massive buildings, and so numerous in number

$b$. Do not improve building periods.

c. Present difficulties in realization, the masonry surfaces are rough, the deep mortar joints require high material consumption, and exclude their correct connection with FRP

3. In the third attempt, some columns were added to the first 2 floors. Practically, this is more feasible especially for construction site opportunities, improves the period in the first mode, improves the displacements and stresses in the wall panels. The columns are fixed all in the perimeter, where their realization is more possible. Their positioning is shown in the figure below, in the plan, and in 3D.

After the third intervention made in the Etabs model, the following parameters changed:
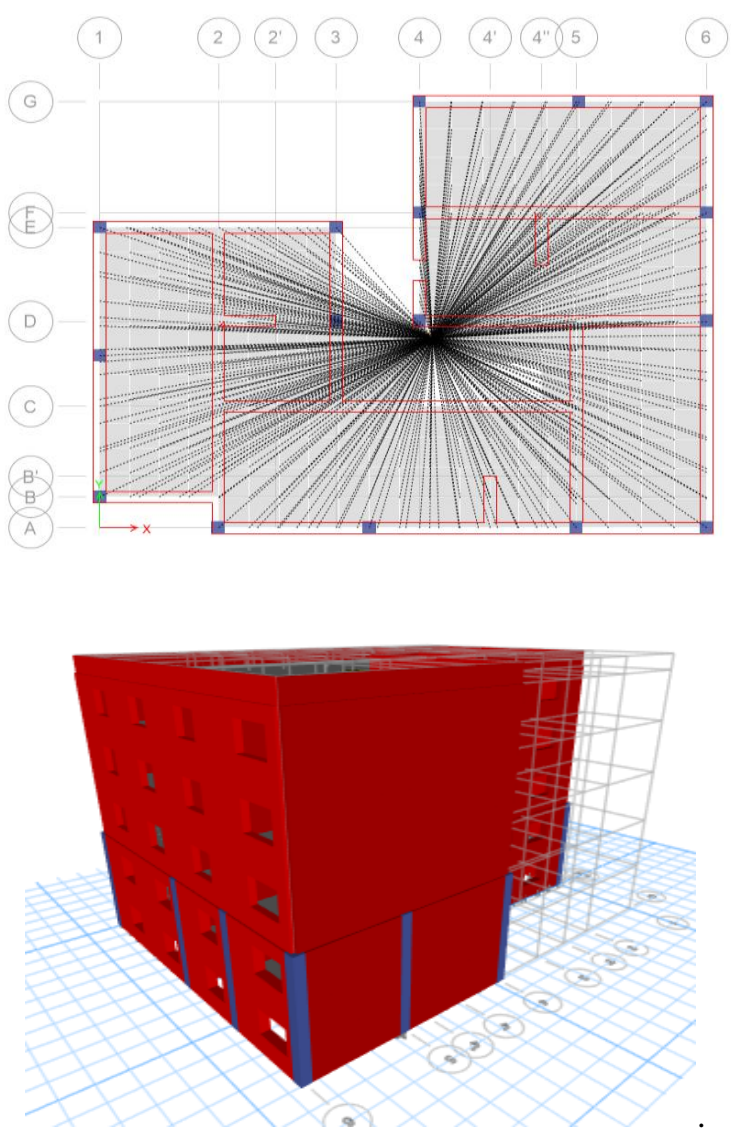

Fig. 10. The columns position in the plan and in 3D

a. Periods in the first modal form are reduced to the value:

\section{Mode 1 - Period 0.352056254329364}

The allowed period is $[\mathrm{T}]=0.365 \mathrm{sec}$.

$b$. The max displacements for ELY comb, declined to order:

$$
\mathrm{Uy}=28.13 \mathrm{~mm}
$$

They are now much smaller than the allowable displacements, $[\mathrm{Ux}]$ and $[\mathrm{Uy}]=7.1 \mathrm{~cm}$.

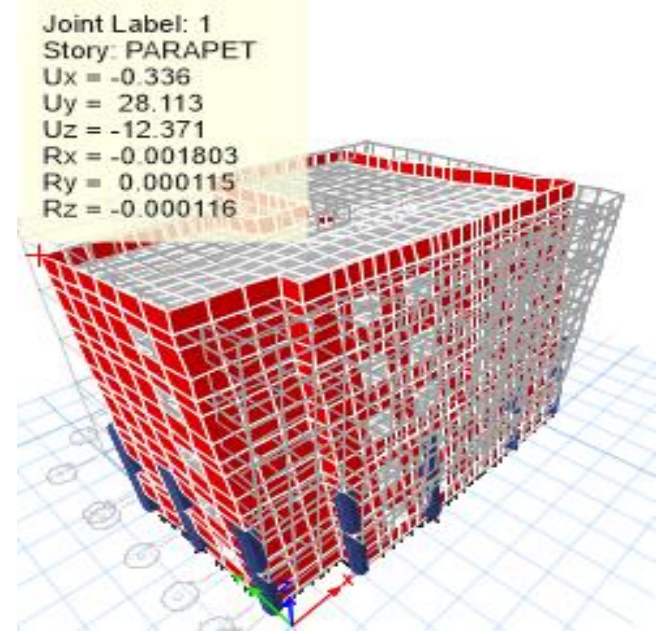

Fig. 11. The max displacements for ELY comb, in the joint 1, for the reinforced building.

c. Compressive and tensile stresses were significantly reduced in the entire masonry. Only at some separate points, for the combination ELY, they exceed the allowed values. But they are very few compared to the situation without reinforcing columns. Below, for the materialization of this idea, are referring to main points and the respective axes where stresses exceed the allowed values on the wall panels.

Axis 6:

Max $=1.51$ at $[18.42,13.4188,0] ;$ Min $=-1.86$ at $[18.42,13.4188,7.7778]$

Axis 4:

Max $=1.35$ at $[9.7,13.87,8.4]$ : Min $=-1.61$ at $[9.7,12.8672,7.7778]$

Axis 2:

$\operatorname{Max}=1.21$ at $[3.6,4.4423,0]: \operatorname{Min}=-1.76$ at $[3.6,0,8.4]$

Some conventional reinforcement interventions may improve this situation, but they are outside the framework and the purpose of this material

\section{REFERENCES}

[1] B. Furiozzi,C. Messina, L. Paolini, Manual for the Calculation of Structural Elements, New Edition, 2007.

[2] Isai Clemente, Structural Design Course, Lecturer at the University of Trieste, 2009/10

[3] Markel Baballëku, Structural Damage Assessment in Education System Buildings, Tirana, November 2014.

[4] Eurocode EC6, EC8.

[5] Academy of Sciences, Tirana KTP-N.2-89. Technical Design Conditions, 1989.

[6] Kerstin Lang, Seismic Vulnerability of Existing Buildings, Zurich Institute of Structural Engineering, Swiss Federal Institute of Technology, February 2002.

[7] Central Archive of the Ministry of Construction, Tirana

[8] Alberto Antonelli ${ }^{\mathrm{a}}$, Michele Betti ${ }^{\mathrm{a}}$, Maria Luisa Del Savio ${ }^{\mathrm{b}}$, Luciano Galano $^{\mathrm{a}}$, Maurizio Orlando ${ }^{\mathrm{a}}$. "Methods for Seismic Analysis of Existing Masonry Buildings"2010. 


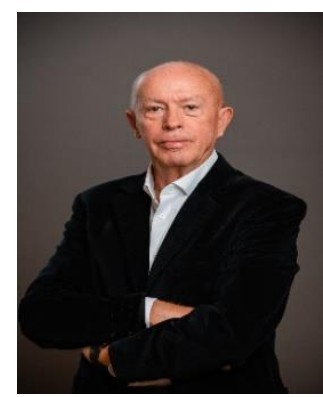

Mr Petraq Koka graduated from the Polytechnic University of Tirana in 1979, in the branch of civil engineering. He unified this degree with that of the Polytechnic University of Athens in 1992.

He has been accredited in the field of teaching, as an external lecturer at Tirana University, since 1984.

$\mathrm{He}$ is the author of many important constructive projects of considerable difficulty, realized mainly in the cities of Tirana and Durres.

Since 1995 he is the Technical Director of the Construction-Project Company "Speed Engineers" ltd. He also is currently a lecturer at UET (Tirana European University). 